\title{
Improving the quality of people's lives as a condition for sustainable development of the municipality of the Khimki city district administration
}

\author{
Marina D. Samakaeva ${ }^{*}$, , Irina N. Kovalyova ${ }^{2}$, Vladimir M. Voblikov ${ }^{3}$ \\ ${ }^{1}$ Moscow International University, Leningradsky prospect, 17, 125040 Moscow, Russia \\ ${ }^{2}$ Bauman Moscow state Technical University, 2nd Baumanskaya St., 5, building 1, 105005 Moscow, \\ Russia \\ ${ }^{3}$ Russian International Academy for Tourism (RIAT), Khimky city area, micro district Skhodnya, \\ Oktyabrskaya street, 10, 141420 Moscow region, Russia
}

\begin{abstract}
Currently, the quality of life of the population is determined by economic, social conditions, and the standard of living of people. In this regard, it is necessary to pay more attention to the development of the socioeconomic sphere, the comprehensive introduction of new modern technologies that increase the level of comfort, quality of living, and accessibility of the environment. These and other factors largely determine its stability and stability. The integrated approach and experience of innovative development of the municipality of the Khimki city district administration can be used in many other regions of our country.
\end{abstract}

\section{Introduction}

Local self-government is carried out in the interests of the entire population of the municipality to improve the quality of its life $[3,5,7,9,8,10]$. Therefore, the concept of sustainable development for improving the quality of life of people has become an instrument of modern municipal policy [11].

WHO defines the quality of life as "the individual's perception of his position in life in the context of the culture and value system in which the individual lives, and concerning the goals, expectations, standards, and interests of that individual". Thus, the quality of human life is determined not only by economic and social conditions but also by the quality of the environment of his existence. The category of environmental quality is closely related to the concept of sustainable development of territories $[1,5,6,8,11]$.

\footnotetext{
* Corresponding author: samakaeva-m@yandex.ru
} 


\section{Materials and Methods}

We assume that the sustainable development of the municipality of the Khimki city district administration largely depends on the quality of the living environment of people and their assessment.

To confirm this hypothesis, we used a systematic approach and the following scientific methods, such as observation, analysis, and synthesis, induction and deduction, scientific logic, extrapolation, abstraction, graphic method, as well as research data conducted by the Financial University under the Government of the Russian Federation, which presents the cities of Russia with the highest quality of life.

\section{Results and Discussion}

It should be noted that Khimki entered the TOP-30 leading cities of the country $[2,4]$.

According to various indicators, the Khimki district surpassed other municipalities of the Moscow region and became the only one in the ranking from the region. According to the head of the city district Dmitrii Voloshin, such significant successes were achieved thanks to the programs of the Governor of the Moscow Region A.Iu. Vorobiev, aimed at improving the quality of life of the population. The modern territory of Khimki locates 36 comfortable and modern recreation areas $[4,12]$.

The district authorities pay special attention to the development of the social sphere. For 6 years, 32 kindergartens have been built on the territory of the district, which is a record among the municipalities of the region [4]. In total, 59 social infrastructure facilities have been built on the territory of Khimki over the past 6 years. Also, over 6 years, 47 teachers received apartments. More than 250 yards have been comprehensively landscaped, more than 1.5 million square meters of roadway have been reconstructed $[2,4,10]$.

The final index of the quality of life in Russian cities was based on such indicators as the quality of medical care, the state of the road economy, the development of culture and education, the work of housing and communal services, and the volume of housing construction, the assessment of the work of city authorities, and the assessment of the convenience of the city for life by the population $[2,4,9,8,10]$.

Khimki ranks 27th and "neighbors" Kaliningrad and Vladimir in the top list.

Khimki presented its achievements and projects within the framework of Russian Energy Week. The development vector of the urban district is aimed at reducing energy consumption, environmental friendliness, and the controllability of these processes. The work includes almost all sectors: transport, education, housing, and communal services, construction. Recently, the first electric bus in the region has been launched in Khimki, the plans include the development of gas-fueled transport and the installation of charging stations for electric vehicles. All of these are part of the global Smart City project.

A major heat metering and distribution project is being successfully implemented in schools and administrative buildings in the district. At present, 46 schools and kindergartens are equipped with individual heating units.

Also, in 2019, the "Light City" program involves replacing all 11,500 poles and the same number of lamps, as well as $67 \mathrm{~km}$ of street lighting lines in Khimki [9].

The Khimki city district administration plans to create the first energy efficiency department in Russia, which will monitor and optimize energy consumption.

In Khimki, new energy-saving light sensors are being introduced that will turn off the light at a certain period of the day.

"Time relays" - power switching sensors in multiple dwelling units of the district, which during daylight hours can significantly reduce the consumption of electricity in public places.

In Khimki, "time relays" have already been installed in four residential buildings. 
In 2018, an automated system for accounting for utilities was introduced in Khimki: the installation of special modems for remote transmission and data control was completed. The modern system allows you to monitor the parameters of heat and water supply, transmit readings, and prevent emergencies.

From July 19 to August 19, management companies of the city district removed more than 760 high-rise buildings. The purpose of the action is to put in order the common areas in apartment buildings as soon as possible, by concentrating all forces and means [8].

"Spring cleaning" was initiated by the association of chairmen of councils of multiple dwelling units of the Moscow region.

The final cleaning was carried out in the house No.11 on Oktyabrskaya Street in the Skhodnya micro-district. Here the communal services summed up the results of the action, and the employees of the best brigade received awards.

During 2018, Khimki continued its implementation of the program for the comprehensive improvement of courtyard areas [8]. As part of the program, non-repairable and potentially hazardous sites were dismantled. Modern sites are equipped with a traumatic surface [9]. A variety of small architectural forms and fitness grounds have also appeared.

As part of the comprehensive improvement at each site, the utilities installed additional lighting, landscaped sidewalks and footpaths, and arranged green spaces. Zoning the playground allows separating small children from adolescents to avoid injury. Cameras are also installed using the Safe Region program.

The control over the technical condition of the sites is carried out by the Khimki city prosecutor's office. The department monitors compliance with legislation governing the technical condition of children's playgrounds.

60 new modern sites that fully meet safety requirements appeared in Khimki in 2018 [9].

Also, 7 new recreation areas have appeared within the project "Named Squares". The initiators of the project are companies and enterprises of Khimki, who want to make the district better and more comfortable for residents.

Modern public spaces are equipped with CCTV cameras connected to the Safe Region system, various small architectural forms, LED lamps, charging devices, free wi-fi, and navigation stands. Each square has its own unique features and unmatched architecture.

In 2018, the grand opening of the Moskva canal embankment, located on the territory of the MAYAK residential complex, took place in Khimki. The embankment starts from the L.N. Tolstoy park and ends at the yacht club. Now the bank of the Moskva canal is framed by a beautiful wrought-iron fence, comfortable benches installed throughout the territory, and a kilometer-long high-quality granite walking area. Free wi-fi, video surveillance cameras, and security. The descent to the embankment is designed with a specific idea, decorated with an original composition - "Hippos" - made in the Tsereteli workshop.

Improvement of the recreation area of L.N. Tolstoy park and the embankment. Two types of maples were chosen for planting, designed to form a colorful central alley, especially in the autumn. Work on arranging the playground with modern play systems, roads, and paths, and an alley with navigation and stylized multi-level lighting have been completed. Information stands were also installed in the park. Here are reference materials about the inhabitants of the park, the Moskva Canal and the Khimka River, photographs of the district, and historical information. The developer plans to build a modern playground for basketball, football, and volleyball, as well as a workout area with sports and exercise equipment.

To maintain open sources of fire-fighting water supply in proper condition in Khimki, 21 fire reservoirs are being cleaned. All of them are located in different neighborhoods of the city district. Rescuers cleared the banks of overgrown bushes and trees, as well as the bottom of silt and debris. At the request of the residents, floating duck houses have been installed.

To prevent a spontaneous generation of waste and unauthorized dumps on the territory of the municipality, a people's patrol was created to control the collection and disposal of 
garbage. The numbers of cars that take out the garbage are collected in a separate list to prevent uncontrolled piles of garbage in the city district in the future.

Raids are regularly carried out to prevent unauthorized waste generation and to identify offenders leaving waste in the wrong places. In the city district, the control over the formation of unauthorized dumps is being tightened. As part of the successful implementation of the Safe Region program, the main goal of which is to install CCTV cameras in public places, offenders will be easily detected, the image is displayed in real time on the monitors of the MBI "Khimspas" and law enforcement agencies of the district [10].

Currently, Khimki has implemented a Separate Waste Collection (SWC) program, which will make it possible to better dispose of garbage waste and reduce the environmental pollution of the territory of the Khimki municipal district.

To date, all neighborhoods in the district have already installed blue containers for recyclable waste, as well as mesh containers for collecting plastic.

Greenpeace Russia has compiled a rating of the availability of infrastructure for separate waste collection in Russian cities. The list includes more than 160 cities with a population of one hundred thousand people [2].

Due to the implementation of a pilot project for separate waste collection, Khimki entered the TOP-10 ranking in its category.

The construction of the museum complex, located in L.N. Tolstoy park, has been completed. The museum includes 10 exhibition halls, as well as a special room for storing exhibits equipped with humidity and temperature sensors.

The area near the museum complex was landscaped. Paths we arranged here, a lawn was planted, and modern lighting was installed. One of the features of the complex is the viewpoint, where a view of the Moscow Canal opens.

This year, the first fast-charging station appeared in Khimki under the program of the Unified Charging Infrastructure of the Moscow Region, implemented by the Ministry of Energy of the Moscow Region.

The modern station was opened on the eve of the FIFA World Cup and is located at the exit from the Leningradskoye Highway near Sheremetyevo International Airport. This station is the first project near Moscow.

A new type of transport that appeared in Khimki is electric buses with a dynamic charging system, equipped with chargers for gadgets, video surveillance cameras, and anti-vandal glass coating. Passengers with limited mobility can easily get into the cabin.

The administration of the Khimki city district conducts daily work to monitor the territory and suppress violations of the current legislation in the field of outdoor advertising, conducts weekly raids to identify these facts.

Medical institutions of Khimki have been equipped with modern and technological equipment. For example, the polyclinic of the Levoberezhny micro-district received a new mammography machine, and SAHF MR "Khimki Central Clinical Hospital" received anesthesia equipment and breathing apparatus for the department of anesthesiology and resuscitation, X-ray equipment with the possibility of digital imaging for the department of traumatology, endoscopic equipment and apparatus for ultrasound diagnostics. The new technology is more efficient and fully complies with international medical standards. Also, the hospital opened the district's first palliative care unit this year.

On the eve of the new academic year, the Ministry of Education of the Moscow Region has published a 100 best schools ranking in the region.

The ranking included 8 schools in Khimki.

The main assessment criteria were the quality of teaching, the organization, and informatization of the educational process, the number of 100-ball students, the success of students at the All-Russian and international Olympiads, as well as the technical equipment of the classrooms. 
In 2018, the Khimki urban district won the silver medal in the competition for the implementation of the Ready for Labor and Defense (TRP) complex at the end of 2017. The organizing committee evaluated the work of the participants according to seven indicators. The city district of Khimki took second place.

The L.N. Tolstoy Khimki Park of Culture and Leisure entered the top three parks of the Moscow region. This year, the contestants were evaluated according to 47 criteria, including the presence of a park development concept, a Safe Region-integrated video surveillance system, its website, and a daily event poster. The ranking was compiled by the Ministry of Culture of the Moscow Region.

In modern Khimki, a whole range of measures is being implemented to support lowincome elderly citizens. The various support activities include a job placement assistance program. Small and medium-sized businesses help residents of the older generation find work.

Entrepreneurs of Khimki implementing various programs of assistance and support for privileged categories of citizens through their active interaction with the municipal administration.

One of the most important programs is assistance in finding a job for retirees. The most popular jobs are in healthcare. In Khimki, they are represented not only by budgetary healthcare institutions but also by specialized medical clinics.

For the convenience of residents, a service was created on the website of the education department of the urban district to post the required registration documents. The service is available on the website of the Khimki City District Education Department: himki-edu.ru. An application can be filled in in the "My Documents" multifunctional center. The parent can use the guest's computer, as well as receive detailed advice from the employee.

Thus, the Khimki administration is actively involved in landscaping and improving the quality of life of the population.

The result of this work was an increase in the satisfaction of city residents and a decrease in the number of calls to the Administration (Figure 1).

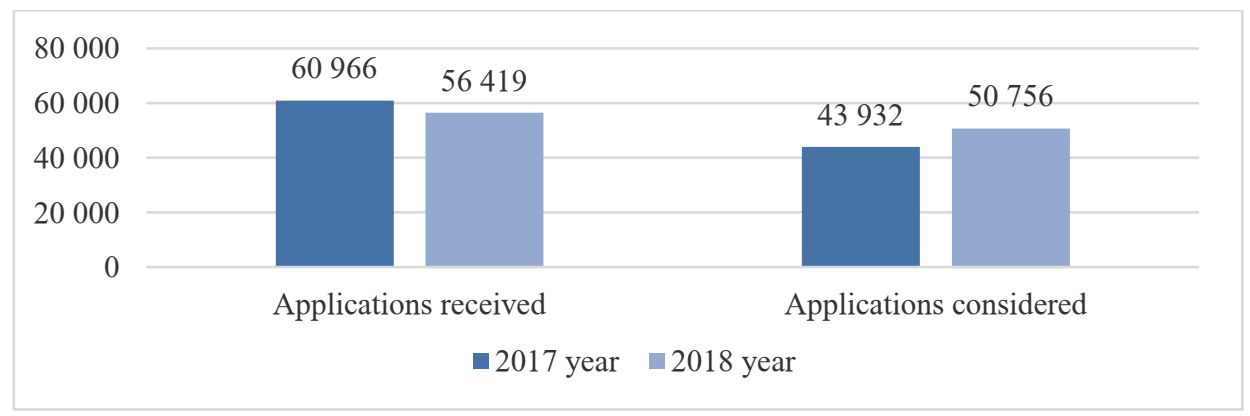

Fig. 1 Appeals of the residents of Khimki to the Administration and their consideration [8]

We should also note the improved quality of consideration of citizens' appeals - if, in $2017,72.05 \%$ of received appeals were considered, then in 2018 , the share of considerations increased to $89 \%$ (Figure 2). 
2017 year

$$
\text { Applications left }
$$$$
\text { considered } 25 \%
$$

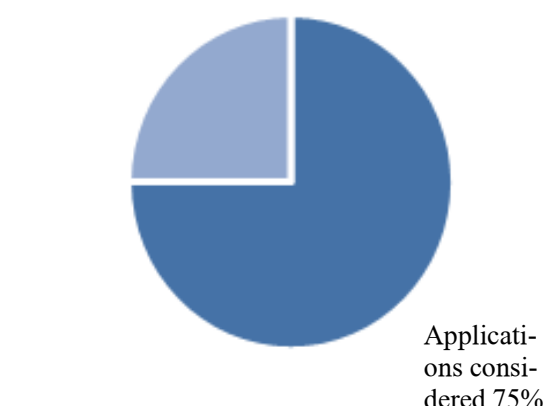

2018 year

Applications left considered $11 \%$

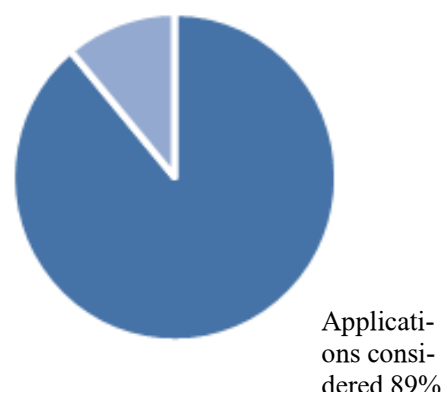

Fig. 2. The share of consideration of citizens' appeals in 2017-2018, \%

\section{Conclusion}

Thus, the main directions in the implementation of sustainable development of the municipality of the Khimki city district administration are:

- a unified urban policy and the execution of legal acts of the city for integrated innovative development of the region;

- creation of favorable conditions for the life of the population and health protection;

- accessible and affordable education and culture, social protection;

- assistance in complex development, improvement, and maintenance of the territory of the urban district $[1,3,7,11]$.

Organization of territorial public self-government on the territory of the considered district with the participation of associations of homeowners, the population and other public bodies; interaction with the public, commercial, and non-profit organizations, as well as the population to create jobs, develop small business, partnership and consent, improve the quality of the living environment of people are priority areas in the sustainable development of the Khimki city district administration.

This experience, in our opinion, requires further study and can be suggested for implementation in other regions of our country.

\section{References}

1. E.N. Agapova, Service in Russia and abroad in 2009, https://cyberleninka.ru/

2. The cities with the highest quality of life. Research of the Financial University under the Government of the Russian Federation on the quality of life in Russian cities, https://rg.ru/

3. Ia.Ia. Kail, V.S. Epimina, R.M. Lamzin, State and municipal administration. Research notes, 4 (2017), https://cyberleninka.ru/

4. I.N. Kovalyova, O.B. Skripnik, D.S. Petrosian, S.A. Lochan, Audit and financial analysis, 3-4, 483 (2017), https://auditfin.com/

5. I.N. Kovalyova, O.B. Skripnik, D.S. Petrosian, S.A. Lochan, Audit and financial analysis, 5-6, 365 (2017), https://auditfin.com/ 
6. E.M. Kliuchnikova, Modern problems of science and education, 5 (2013), https://www.science-education.ru/

7. E. L. Morozova, Bulletin of Kemerovo State University. Series: Political, sociological, and economic sciences, 3, 35 (2018), https://cyberleninka.ru/

8. Open budget of Khimki, http://budget.admhimki.ru/

9. Report of the head of the urban district of Khimki on the work done in 2018, www.admhimki.ru

10. D.R. Sarkisian, Economy and society, 9 (76) (2020), www.iupr.ru

11. M.Iu. Sheresheva, M.S. Oborin, A.A. Kostanian, Ars Admimstrandi (The Art of Management), 2, 289 (2017), https://cyberleninka.ru/

12. Y.N. Vorobyov, D.D. Burkaltseva, I.N. Kovalyova, L.M. Borsch, S.V. Gerasimova Journal of Advanced Research in Law and Economics, 2, 729 (2018), https://www.scopus.com/ 